\title{
Good vibrations-better care for lung cancer patients
}

\author{
Scott J. Swanson, MD
}

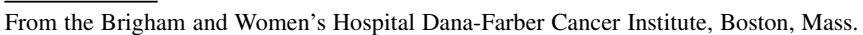

Disclosures: Author has nothing to disclose with regard to commercial support.

Received for publication April 2, 2018; accepted for publication April 6, 2018; available ahead of print May 1, 2018.

Address for reprints: Scott J. Swanson, MD, Brigham and Women's Hospital Dana-Farber Cancer Institute, 75 Francis St, Boston, MA 02115 (E-mail: sjswanson@partners.org).

J Thorac Cardiovasc Surg 2019;157:378-9

$0022-5223 / \$ 36.00$

Copyright (c) 2018 by The American Association for Thoracic Surgery

https://doi.org/10.1016/j.jtcvs.2018.04.022

The best treatment of early-stage lung cancer is surgical resection. Over the past nearly 25 years, the standard has evolved such that a thoracoscopic approach is superior to a resection via a thoracotomy. These benefits include morbidity, mortality, length of hospital stay, hospital discharge independence, pain scores, pulmonary function, and in several meta-analyses long-term survival. ${ }^{1}$ The magnitude of the benefit is increased in those patients who are more limited, such as older patients, patients with diminished pulmonary function, or other severe comorbidities. ${ }^{2}$ With such overwhelming evidence, all patients must be having their lobectomy or segmentectomy performed with a thoracoscope or possibly with the assistance of a robot.

Surprisingly and unfortunately, this is not the case. Clearly adoption has improved and depending on the database used to examine this, about half of all pulmonary lobectomies are done via a minimally invasive approach. We must do better. The answer lies in the reason for lack of adoption. Exposure to adequate training is probably the number one reason, and this situation is significantly improving as current trainees who are capable get out into practice and spread the word. Second on the list is fear of uncontrolled pulmonary vascular bleeding. Improvement in stapling technology has helped a great deal in this regard as well as education on how to manage such a problem. Hemostatic agents are available that can help control significant bleeding.

Yet in discussing this problem, surgeons are still highly concerned. With the advent of surgical energy devices (ultrasonic and electrothermal), surgeons have learned to divide various types of blood vessels quickly, efficiently, and safely. In 2007, the first paper examining the use of ultrasonic energy to divide pulmonary vessels in an animal model was published, ${ }^{3}$ and this was followed up with safety and indications for use in humans. ${ }^{4}$ Since this time, other groups have identified similar safety and size parameters. ${ }^{5}$ Okada and colleagues, ${ }^{6}$ as reported in this issue of the Jour$n a l$, are to be congratulated for further advancing this field by outlining parameters for pulmonary vascular control

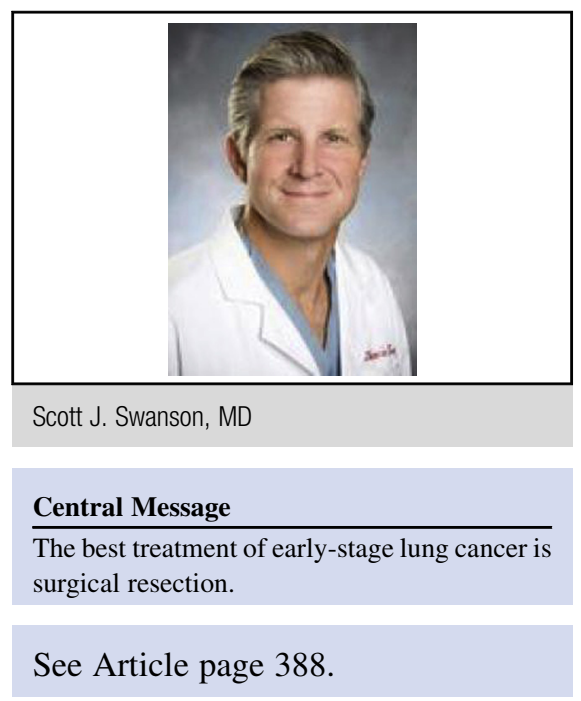

using electrothermal energy. There is no question that small, curved devices that can dissect and more easily enter limited spaces have improved the ease and safety of dividing pulmonary vessels. This will translate into easier and safer minimally invasive pulmonary resection.

Thoracic surgeons must embrace this. We must perform all early-stage lung cancer resections using minimally invasive techniques. Our mortality needs to be near zero, with length of hospital stay less than 24 hours and without significant pain using band-aid type incisions if we want to continue to give our patients the best treatment rather than compromise therapies such as focused radiation or perhaps evolving ablative techniques. With the ability to precisely and accurately resect the tumor with its draining vessels and lymph nodes while removing the cancer for advanced study, surgical resection should remain the gold standard as long as we continue to improve our outcomes. Pulmonary vascular dissection and division using energy is a clear and quantum advance!

\section{References}

1. Nicastri DG, Wisnivesky JP, Litle VR, Yun J, Chin C, Dembitzer FR, et al. Thoracoscopic lobectomy: report on safety, discharge independence, pain and chemotherapy tolerance. J Thorac Cardiovasc Surg. 2008;135: 642-7.

2. Demmy TL, Curtis JJ. Minimally invasive lobectomy directed toward frail and high-risk patients: a case-control study. Ann Thorac Surg. 1999;68: 194-200.

3. Nicastri DG, Wu M, Yun J, Swanson SJ. Evaluation of efficacy of an ultrasonic scalpel for pulmonary vascular ligation in an animal model. J Thorac Cardiovasc Surg. 2007; 134:160-4.

4. White A, Kucukak S, Lee DN, Swanson SJ. Energy-based ligation of pulmonary vessels: a six-year experience with ultrasonic shears in video-assisted thoracoscopic lobectomy and segmentectomy. Ann Thorac Surg. 2016;101:133-7. 
5. Goudie E, Thiffault V, Jouquan A, Lafontaine E, Ferraro P, Liberman M. Pulmonary artery sealing with ultrasonic energy in open lobectomy. A Phase 1 clinical trial. J Thorac Cardiovasc Surg. 2017;153:1600-7.
6. Okada M, Miyata Y, Takamochi K, Tsutani Y, Oh S, Suzuki K. Prospective feasibility study of sealing pulmonary vessels with energy in lung surgery. J Thorac Cardiovasc Surg. 2019;157:388-95. 